\title{
Sensitivity of bare soil albedo to surface soil moisture on the moraine of the Zongo glacier (Bolivia)
}

\author{
S. Gascoin, ${ }^{1}$ A. Ducharne, ${ }^{1}$ P. Ribstein, ${ }^{1}$ E. Perroy, ${ }^{2}$ and P. Wagnon ${ }^{3}$ \\ Received 20 October 2008; revised 28 November 2008; accepted 5 December 2008; published 22 January 2009.
}

[1] The dependence of bare soil albedo on soil water content is investigated using in situ data collected on the moraine of an Andean glacier (Bolivia). This study demonstrates a high negative correlation between the two variables that is best approximated by an exponential function, in agreement with previous studies. More importantly, the average snow-free albedo value during the rainy season is $40 \%$ lower than during the dry season $(0.16$ vs. 0.26$)$. These results are relevant for climate and land surface modeling applications, where bare soil albedo is often considered as a constant parameter. Citation: Gascoin, S., A. Ducharne, P. Ribstein, E. Perroy, and P. Wagnon (2009), Sensitivity of bare soil albedo to surface soil moisture on the moraine of the Zongo glacier (Bolivia), Geophys. Res. Lett., 36, L02405, doi:10.1029/ 2008 GL036377.

\section{Introduction}

[2] Albedo, defined as the ratio of reflected to incoming solar radiation is a fundamental parameter in climate modeling. The terrestrial albedo, which depends on local vegetation and soil characteristics, directly modulates the energy balance of the land surface.

[3] Therefore, the variation of land surface albedo exerts a strong influence on climate, as shown for instance by numerous studies of deforestation or afforestation [Dirmeyer and Shukla, 1994; Betts, 2000; Bala et al., 2007].

[4] In such studies, the tools used to represent the land surface component of the climate system are Land Surface Models (LSMs), sets of equations that simulate surface water and energy fluxes and may be coupled to an atmospheric general circulation model, or driven by an atmospheric forcing data set.

[5] Our study deals with bare soil albedo. It is known that variations of soil albedo occur because of soil moisture variations. However, bare soil albedo is set constant in many LSMs applications. According to Zeng [2005], soil moisture effect on albedo is not taken into account in the LSMs of the National Centers for Environmental Prediction (NCEP) and of the European Centre for Medium-Range Weather Forecasts (ECMWF).

[6] It is worth noting that the estimated area of bare soil on Earth is $35 \times 10^{6} \mathrm{~km}^{2}$, i.e., $7 \%$ of the Earth's surface area or $26 \%$ of the total land surface area, excluding Antarctica [Sterling and Ducharne, 2008]. The regions

\footnotetext{
${ }^{1}$ UMR7619 Sisyphe, Université Pierre et Marie Curie, CNRS, Paris, France.

${ }^{2}$ Great Ice, Instituto de Hidráulica e Hidrologia, La Paz, Bolivia.

${ }^{3}$ Great Ice, IRD, LGGE, Grenoble, France.
}

with the largest bare soil surfaces are the arid to semi-arid areas (e.g., Sahel region, Middle East, and Gobi desert), but large bare soil surfaces also occur in high altitude mountainous areas and temporarily in many cultivated areas.

[7] The darkening of soil when it changes from dry to moist is a familiar observation that was first addressed theoretically by Angström [1925]. It is due to the fact that water replacing air in the pores tends to increase the likelihood of light absorption by the surface. Kondratyev [1969] has compiled the values of wet and dry albedo for several soil covers.

[8] Idso et al. [1975] showed in a pioneering field study that bare soil albedo is a linear function of the water content in the uppermost layer of the soil $(0.2-\mathrm{cm}$ to $10-\mathrm{cm})$. This result was obtained in Arizona on a calcareous loam soil, after irrigation and is still a major reference for the land surface modeling community. For example, Pitman et al. [1991], Acs and Hantel [1998], and Matsui et al. [2007] included such a linear equation in their LSM.

[9] But Idso's work has been challenged by more recent studies. Lobell and Asner [2002] have brought laboratorybased evidences that an exponential relationship is more appropriate for several soil types. Duke and Guérif [1998] give the parameters for exponentially decreasing soil reflectance-water content functions corresponding to three soil types (silty loam, clay loam, chalky soils), but their results are based on remote sensing and soil moisture is derived from an empirical relation. Moreover, they consider a soil layer depth of $1-\mathrm{mm}$, which is too thin to be appropriate for most land surface models. Liu et al. [2002] indicate that different soil reflectances measured across the solar spectrum decrease with soil moisture up to a critical point and then increase before saturation.

[10] Most of these studies are based on laboratory experiments [Twomey et al., 1986; Lobell and Asner, 2002; Liu et al., 2002] or theoretical approach [Ishida et al., 1991; Twomey et al., 1986]. Because they are generally motivated by the fact that albedo (or surface reflectance measured in the solar spectrum) is a potential proxy for soil moisture remote sensing, the authors try to establish a relationship as general as possible by using a large number of soil types.

[11] To the authors' knowledge, the only in situ study after Idso et al. [1975] is reported by Wang et al. [2005], who also showed that bare soil albedo dependence on soil moisture on the Tibetan Plateau is nonlinear, but did not observe an opposite trend at high water content (Table 1).

[12] In this paper we use albedo and moisture data collected on the moraine of a Bolivian glacier. The site, the measuring instruments and the data processing are described in 
Table 1. Summary of Studies Addressing the Dependence of Bare Soil Albedo (or Reflectance) on Soil Moisture

\begin{tabular}{|c|c|c|c|c|}
\hline Reference & Soil Type & $\begin{array}{l}\text { Soil Moisture } \\
\text { Measurement } \\
\text { Depth }\end{array}$ & Type of Study & Relationship \\
\hline Idso et al. [1975] & Avondale loam & $0.02-10 \mathrm{~cm}$ & Field & Linear \\
\hline Duke and Guérif [1998] & various ( 3 soils) & $1 \mathrm{~mm}$ & Remote sensing & Exponential \\
\hline Lobell and Asner [2002] & various (4 soils) & $1 \mathrm{~mm}$ & Laboratory & Exponential \\
\hline Liu et al. [2002] & various (10 soils) & $1.5 \mathrm{~cm}$ & Laboratory & Exponential $^{\mathrm{a}}$ \\
\hline Wang et al. [2005] & clay & $3 \mathrm{~cm}$ & Field & Exponential \\
\hline
\end{tabular}

${ }^{\mathrm{a} O n l y}$ for low to medium water content.

section 2. The correlation between bare soil albedo and soil moisture is presented and discussed in section 3 .

\section{Site Description, Data and Method}

\subsection{Site Description}

[13] We use data from an automatic weather station (hereinafter referred as ORE-AWS) located on the lateral moraine of the Zongo glacier $\left(68^{\circ} 10^{\prime} \mathrm{W}, 16^{\circ} 15^{\prime} \mathrm{S}\right.$, altitude $5050 \mathrm{~m}$ a.s.l) in the Cordillera Real, near La Paz, Bolivia (Figure 1). The soil particles come from the weathering of a crystalline silicate bedrock. Except for the bedrock outcrops, the non-glacierized areas are mainly covered by glacial deposits. The vegetation cover becomes significant below $4800 \mathrm{~m}$ a.s.1., in wetlands along the Zongo River. In general, bare soil areas are large in the Central Andes, considering the fact that the vegetation is sparse above $3500 \mathrm{~m}$ a.s.l. The local climate is characterized by the alternation of a rainy season during austral summer and a dry season during austral winter. The annual precipitation varies between $600 \mathrm{~mm}$ and $1200 \mathrm{~mm}$ [Wagnon et al., 2001], but the night-time temperatures are too low to allow the development of vegetation.

\subsection{Measurements}

[14] The main study site is located inside the ORE-AWS perimeter, where albedo and soil moisture are continuously monitored among other meteorological parameters. In addition, albedo and soil moisture measurements have been performed at two different flat sites located on the moraine surrounding the glacier (noted LA and BG; see Figure 1). LA site is located near a small lake and BG is located on the flat area near the glacier mouth.

[15] For each of the three sites, 15 soil samples of approximately $50 \mathrm{~g}$ have been collected and mixed to make an average sample [AFNOR, 1992]. The granulometric analysis indicate that the three average samples belong to the sand class in the USDA triangle (Table 2).

[16] In the ORE-AWS, instantaneous albedo is computed from incident and reflected shortwave radiations that are measured at a $10 \mathrm{~s}$ interval by two CM3 Kipp \& Zonen pyranometers (waveband $305 \mathrm{~nm}$ to $2800 \mathrm{~nm}$ ). The mean albedo value is recorded every $30 \mathrm{~min}$ to an accuracy of $5 \%$. Volumetric water content (VWC, volume of water per volume of soil) is logged every hour in the top $5-\mathrm{cm}$ using a ThetaProbe Soil Moisture Sensor which was set up on 7 November 2007. The study period ends on 21 June 2008 and thus is long enough to observe the whole rainy season which roughly begins in December and ends in March.

[17] The same devices were used to measure albedo and soil moisture outside of the ORE-AWS, at sites LA and BG. To this purpose, a portable AWS (PAWS), similarly equipped with two CM3 Kipp \& Zonen pyranometers, has been moved on the moraine. At each site, the VWC is measured at 15 different spots near the PAWS using another ThetaProbe sensor, with special care taken that the soil surface be not disturbed in the pyranometer footprint. Note that these measurements were taken on two days running at site LA, as a rainfall occurred during the night.

[18] In addition, the soil has been artificially irrigated during $30 \mathrm{~min}$ at site LA. For this experiment, the soil moisture sensor was buried under the pyranometer in the same way as in the ORE-AWS.

[19] Specific calibration of the ThetaProbe sensors was performed in laboratory by oven-drying the average soil samples at $105^{\circ} \mathrm{C}$ for $24 \mathrm{~h}$. The soil volumetric water content (VWC) is thereby estimated with an accuracy of $0.05 \mathrm{~m}^{3} / \mathrm{m}^{3}$ [Delta-T Devices, 1999].

\subsection{Albedo Data Processing}

[20] The continuous albedo measurements in the OREAWS are strongly affected by the solar zenith angle
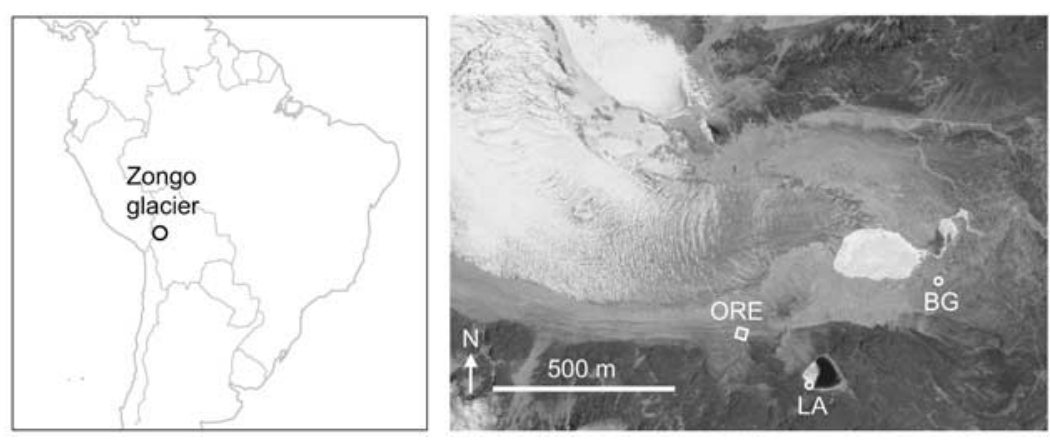

Figure 1. (left) Localization of the Zongo glacier. (right) Aerial view of the study area and localization of the ORE-AWS and study sites LA and BG around the Zongo glacier. 
Table 2. Soil Granulometry (5 Fractions) of the Three Experimental Sites ORE, LA and BG

\begin{tabular}{lcccc}
\hline & & \multicolumn{3}{c}{ Mass Fraction (\%) } \\
\cline { 3 - 5 } Texture Class & Size $(\mu \mathrm{m})$ & ORE & LA & BG \\
\hline Clay & $<2$ & 1.8 & 2.8 & 1.8 \\
Fine silt & $2-20$ & 2.7 & 3.9 & 1.7 \\
Coarse silt & $20-50$ & 3.1 & 5.0 & 3.5 \\
Fine sand & $50-200$ & 22.2 & 24.1 & 15.7 \\
Coarse sand & $200-2000$ & 70.2 & 64.2 & 77.3 \\
\hline
\end{tabular}

(Figure 2a). Just after sunset or just before sunrise, when the solar zenith angle is high, the soil roughness induces shadowing of the surface, which tends to increase albedo. In the ORE-AWS data, the soil roughness effect on albedo is limited to the very first and last hours of the daylight because the surface is practically flat. Thus, instead of using a theoretical correction which would introduce new parameters [e.g., Twomey et al., 1986], we chose to select the data following an empirical procedure. The period of the day with no significant zenithal effect can be seen using a representation of all daily cycles over the investigated period (Figure 2b). This representation shows that the values measured between 9:00 and 16:30 (local time) are not significantly influenced by the zenith angle (Figure $2 \mathrm{c}$ ). The distribution of the remaining values (Figure $2 \mathrm{~d}$ ) allows us to highlight the snow effect. As soon as snow covers a fraction of the surface under the pyranometer, it tends to increase the albedo value. Only the values between 0 and 0.4 are kept thereafter to filter out most of the values affected by the snow in the soil moisture sensitivity analysis (Figure 2e).

\section{Results and Discussion}

[21] The simultaneous (but with opposite signs) variations of bare soil albedo and VWC clearly appear in the measurements taken at site LA and in the ORE-AWS (Figure 3). Albedo decreases several times in the OREAWS time series and stabilizes after the end of the rainy season. The soil water content is equivalent at the beginning and at the end of the period. Similarly, the latest albedo values are close to the average value at the beginning of the period, demonstrating that the soil surface has not been modified during the rainy season. The albedo values distribution (Figure 2d) shows two well-marked modes that can be related to two different soil moisture conditions. The mode at 0.26 corresponds to a dry soil and the mode at 0.16 to a wet soil in the ORE-AWS. These values are close to the
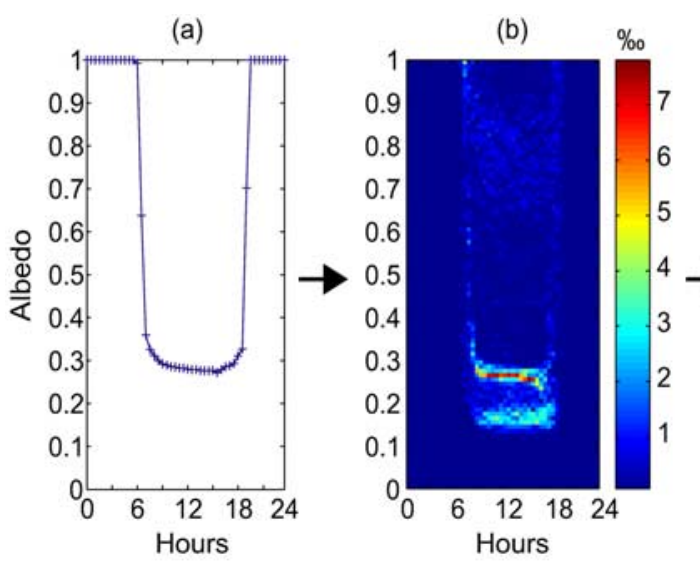

(e)

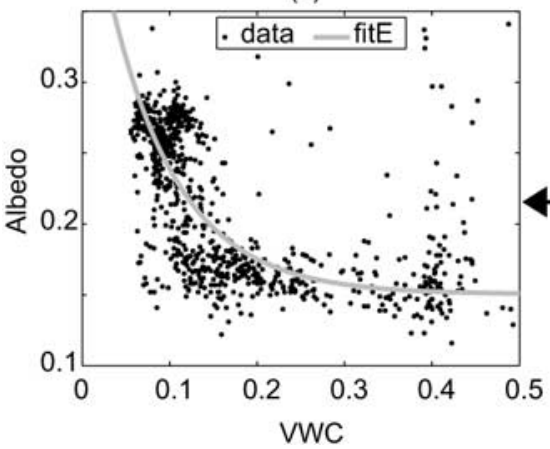

(c)

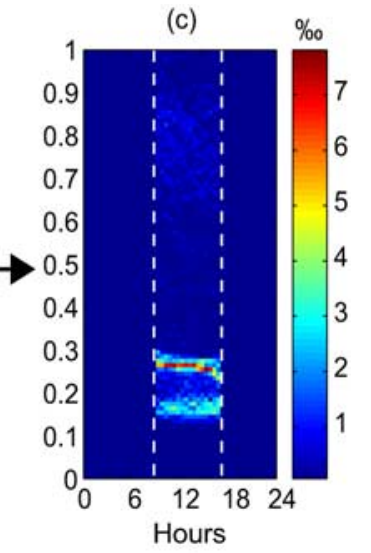

(d)

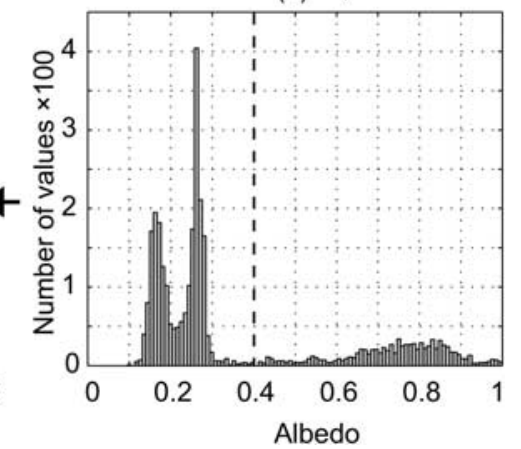

Figure 2. Albedo data processing. (a) Albedo values recorded on 11-Nov-2007 in the ORE-AWS, as an example showing solar zenith angle effect. (b) All albedo values recorded every $30 \mathrm{~min}$ from 07-Nov-2007 to 21-Jun-2008, grouped into 100 classes of albedo along the $\mathrm{y}$-axis and into 48 classes of time of day along the $\mathrm{x}$-axis. The color scale represents the amount of points in each pixel. (c) Same graph after the empirical data selection. Only albedo data recorded between 9:00 and 16:30 are kept. (d) Distribution of the remaining albedo values. Only values lower than 0.4 are considered as not influenced by snow. (e) Snow-free albedo versus VWC (1-hr mean values, data from the ORE-AWS). fitE: fitting curve obtained with an exponential function. 

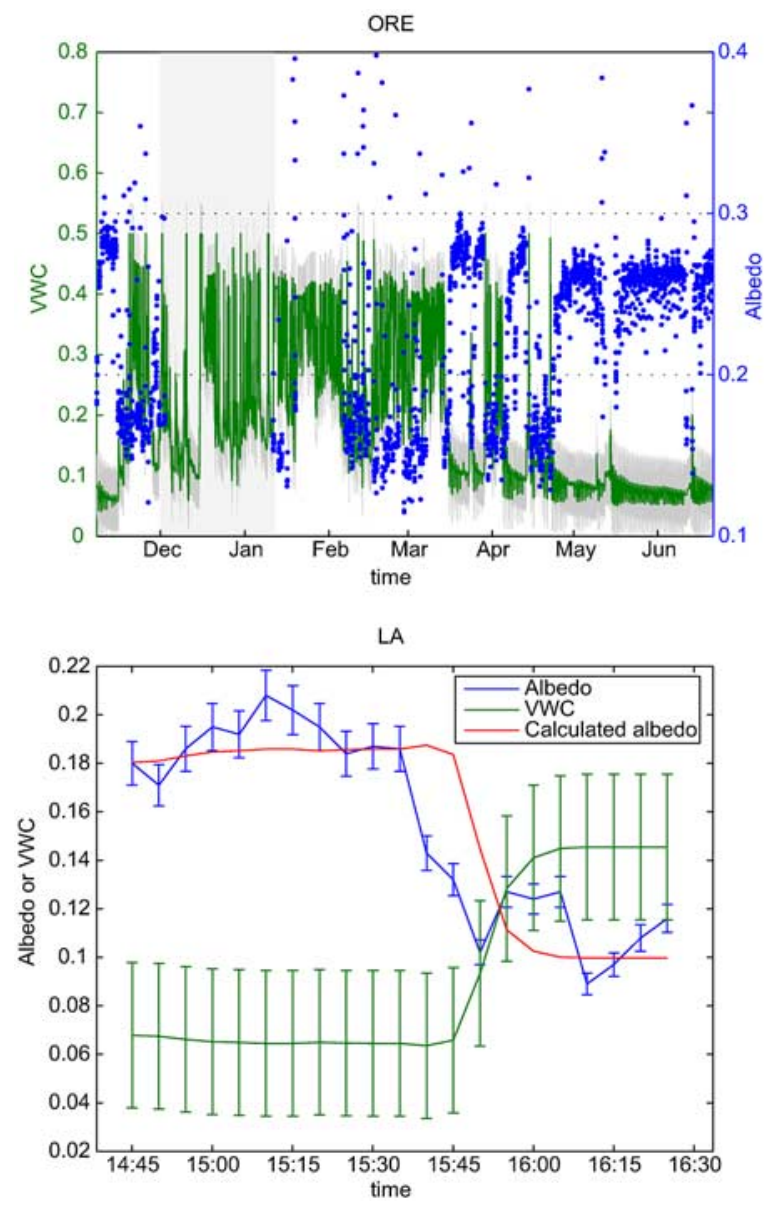

Figure 3. Volumetric water content $\left(V W C\right.$ in $\left.\mathrm{m}^{3} / \mathrm{m}^{3}\right)$ and corrected albedo time series for both sites ORE and LA. (top) Data from the ORE-AWS (1-hr mean values); left y-axis, grey line: VWC and error bars; right y-axis, black dots: soil albedo. The light-grey rectangle in background indicates a data gap in the albedo data set due to datalogger's battery failure. (bottom) Data from the in situ experiment performed at LA site on 14-Nov-2007 (with error bars) and calculated albedo using equation (1).

dry and moist values reported by Kondratyev [1969] for the class "gray earth", i.e., $0.25-0.30$ and $0.10-0.12$, respectively. But the point measurements LA and BG indicate that these values may not be adapted for the whole study area (Table 3). Albedo can vary significantly between soils that come from the same bedrock and that belong to the same texture class. For example, the albedo at LA when the soil is wet $(\mathrm{VWC}=0.27)$ is $60 \%$ of the value measured at $\mathrm{BG}$ for a close water content. The same conclusion can be drawn from the data collected during the irrigation experiment. This is simply due to the fact that the soil color is darker at this site.

[22] Figure 2e clearly shows that the dependence of bare soil albedo on water content in the top 5-cm is nonlinear. A good fit is obtained with the following exponential function $\left(R^{2}=0.67\right.$ and $\left.\operatorname{RMSE}=0.030\right)$ :

$$
\alpha=A \exp (-B \theta)+C
$$

where $\alpha$ is the soil albedo and $\theta$ the VWC.
[23] The best fit coefficients $A=0.31, B=12.7$ and $C=0.15$ are in the range of values found by Lobell and Asner [2002], but Wang et al. [2005] reported a much lower value for the $B$ coefficient ( $B=3.52$, clay soil type).

[24] If the values of albedo and water content are only known for two different soil surface conditions (preferably when the soil is driest and wettest), $A$ and $C$ coefficients can be computed from equation (1). As an example, we used data from the irrigation experiment at LA. Bare soil albedo before irrigation averages 0.18 , corresponding to dry soil $(\mathrm{VWC}=0.068)$ and it drops to 0.1 when VWC increases to 0.145 . These values allow us to compute $A$ and $C$, while the $B$ parameter is taken from the previous fit. Figure 3 shows that the resulting albedo is still properly estimated.

[25] However, the discrepancy between calculated and measured albedo is large when the soil moisture is varying. This discrepancy is due to a short time lag between soil moisture and albedo variations. Indeed, albedo depends on the moisture of the very surface, whereas soil moisture is measured at a 5-cm depth. Moreover, the soil was particularly dry at the beginning of the experiment, which delayed the infiltration.

[26] This phenomenon is a possible explanation as to why several very low albedo values are measured simultaneously with low water content in the ORE-AWS (Figure 2e).

[27] On the other hand, large albedo values are recorded in the ORE-AWS while VWC is close to maximum. This is likely to be linked with the snow occurrence. Indeed, Lejeune et al. [2007] observed that snow pack in this area is ephemeral due to the extremely high solar radiation. The resulting patchy snow cover integrated by the pyranometer may have a high albedo value while the soil is wetted by snow melt.

\section{Conclusion}

[28] The covariation of bare soil albedo and water content has been demonstrated using in situ data collected on the moraine of the Zongo glacier, where cold temperature conditions limit vegetation cover. For this purpose, the ORE weather station is a suitable study site. The local relationship we found seems robust, but the parameters must be carefully examined before application to other regions.

[29] At the annual timescale, snow-free albedo measured during the rainy season is 0.16 , i.e., approximately $40 \%$ lower than during the dry season $(0.26)$. The consequence is a $14 \%$ increase of absorbed incoming solar radiations, so that one can expect a significant impact on the energy balance and consequently on the water balance.

[30] To demonstrate this point, the relationship found between albedo and soil moisture has been included in the

Table 3. Mean Values and Standard Deviations of VWC and Albedo $^{\mathrm{a}}$

\begin{tabular}{ccccccc}
\hline & & \multicolumn{2}{c}{ VWC } & & \multicolumn{2}{c}{ Albedo } \\
\cline { 3 - 4 } \cline { 7 - 7 } Label & Date & Mean & Std & & Mean & Std \\
\hline LA & 14-Nov-2007 & 0.066 & 0.029 & & 0.19 & 0.011 \\
LA & 15-Nov-2007 & 0.27 & 0.077 & & 0.12 & 0.0084 \\
BG & 15-Nov-2007 & 0.33 & 0.029 & & 0.20 & 0.0087 \\
\hline
\end{tabular}

${ }^{\mathrm{a}}$ Each value is computed from 15 measurements (section 2.2). 
energy balance equations of a hydrometeorological model. In comparison with a run in which bare soil albedo is set constant, the result is a $12 \%$ increase of the annual evaporation (S. Gascoin et al., Dependence of bare soil albedo on soil moisture on the moraine of the Zongo glacier (Bolivia): Implicatons for land surface modeling, submitted to Journal of Geophysical Research, 2009).

[31] In conclusion, a global database containing parameters describing the soil albedo and its variation with soil moisture in the top first centimeters would be highly valuable for climate modeling [Liang et al., 2005].

[32] Acknowledgments. Work on Zongo catchment was funded by the French Observatoire de la Recherche en Environnement (ORE) GLACIOCLIM (IRD, French research ministry; see http://www-lgge.ujfgrenoble.fr/ServiceObs/) with the support of Instituto de Hidraulica e Hidrologia, La Paz, Bolivia.

\section{References}

Acs, F., and M. Hantel (1998), The land-surface flux model PROGSURF, Global Planet. Change, 19, 19-34, doi:10.1016/S0921-8181(98)00039-3.

AFNOR (1992), Qualité des sols, Echantillonnage, Méthode de prélèvement déchantillons de sol, Tech. Rep. X31-100, La Plaine Saint-Denis, France.

Angström, A. (1925), The albedo of various surfaces of ground, Geogr. Ann., 7, 323-342.

Bala, G., K. Caldeira, M. Wickett, T. J. Phillips, D. B. Lobell, C. Delire, and A. Mirin (2007), Combined climate and carbon-cycle effects of largescale deforestation, Proc. Natl. Acad. Sci. U. S. A., 104, 6550-6555, doi:10.1073/pnas.0608998104.

Betts, R. (2000), Offset of the potential carbon sink from boreal forestation by decreases in surface albedo, Nature, 408, 187-190, doi:10.1038/ 35041545.

Delta-T Devices (1999), ThetaProbe Soil Moisture Sensor Type ML2x User Manual, vol. 1.21, Cambridge, U.K.

Dirmeyer, P. A., and J. Shukla (1994), Albedo as a modulator of climate response to tropical deforestation, J. Geophys. Res., 99, 20,863-20,877.

Duke, C., and M. Guérif (1998), Crop reflectance estimate errors from the sail model due to spatial and temporal variability of canopy and soil characteristics, Remote Sens. Environ., 66, 286-297, doi:10.1016/ S0034-4257(98)00062-5.

Idso, S., R. Jackson, R. Reginato, B. Kimball, and F. Nakayama (1975), The dependence of bare soils albedo on soil water content, J. Appl. Meteorol., 14, 109-113, doi:10.1175/1520-0450(1975)014<0109: TDOBSA $>2.0 . \mathrm{CO} ; 2$.

Ishida, T., H. Ando, and M. Fukuhara (1991), Estimation of complex refractive index of soil particles and its dependence on soil chemical properties, Remote Sens. Environ., 38, 173-182.
Kondratyev, K. Y. (1969), Radiation in the Atmosphere, Int. Geophys. Ser., vol. 12, 912 pp., Academic, New York.

Lejeune, Y., P. Wagnon, L. Bouilloud, P. Chevallier, P. Etchevers, E. Martin, J.-E. Sicart, and F. Habets (2007), Melting of snow cover in a tropical mountain environment in Bolivia: Processes and modeling, J. Hydrometeorol., 8, 922-937, doi:10.1175/JHM590.1.

Liang, X. Z., et al. (2005), Development of land surface albedo parameterization based on moderate resolution imaging spectroradiometer (MODIS) data, J. Geophys. Res., 110, D11107, doi:10.1029/ 2004JD005579.

Liu, W. D., F. Baret, X. F. Gu, Q. X. Tong, L. F. Zheng, and B. Zhang (2002), Relating soil surface moisture to reflectance, Remote Sens. Environ., 81, 238-246, doi:10.1016/S0034-4257(01)00347-9.

Lobell, D. B., and G. P. Asner (2002), Moisture effects on soil reflectance, Soil Sci. Soc. Am. J., 66, 722-727.

Matsui, T., A. Beltrán-Przekurat, R. A. Pielke, D. Niyogi, and M. B. Coughenour (2007), Continental-scale multiobservation calibration and assessment of Colorado State University Unified Land Model by application of Moderate Resolution Imaging Spectroradiometer (MODIS) surface albedo, J. Geophys. Res., 112, G02028, doi:10.1029/2006JG000229.

Pitman, A. J., Z. L. Yang, J. G. Cogley, and A. Henderson-Sellers (1991), Description of the bare essentials of surface transfer for the Bureau of Meteorology Research Centre AGCM, BMRC Res. Rep. 32, 117 pp., Bur. of Meteorol. Res. Cent., Melbourne, Victoria, Australia.

Sterling, S., and A. Ducharne (2008), Comprehensive data set of global land cover change for land surface model applications, Global Biogeochem. Cycles, 22, GB3017, doi:10.1029/2007GB002959.

Twomey, S. A., C. F. Bohren, and J. L. Mergenthaler (1986), Reflectance and albedo differences between wet and dry surfaces, Appl. Opt., 25, $431-437$.

Wagnon, P., P. Ribstein, B. Francou, and J. E. Sicart (2001), Anomalous heat and mass budget of Glaciar Zongo, Bolivia, during the 1997/98 El Niño year, J. Glaciol., 47, 21-28.

Wang, K. C., P. C. Wang, J. M. Liu, M. Sparrow, S. Haginoya, and X. J. Zhou (2005), Variation of surface albedo and soil thermal parameters with soil moisture content at a semi-desert site on the western Tibetan plateau, Boundarey Layer Meteorol., 116, 117-129, doi:10.1007/s10546004-7403-Z.

Zeng, X. (2005), Overview of soil, vegetation, and snow albedos in weather and climate models, paper presented at 19th Conference on Hydrology, Am. Meteorol. Soc., San Diego, Calif. (Available at http://ams.confex. com/ams/Annual2005/techprogram/paper_88110.htm)

A. Ducharne, S. Gascoin, and P. Ribstein, UMR7619 Sisyphe, Université Pierre et Marie Curie, CNRS, 4 place Jussieu, F-75005 Paris, France. (simon.gascoin@upmc.fr)

E. Perroy, Great Ice, Instituto de Hidráulica e Hidrologia, La Paz, Bolivia.

P. Wagnon, Great Ice, IRD, LGGE, Grenoble BP 96, F-38402 St. Martin d'Hères, France. 